OPEN ACCESS

Edited by:

Marco Tullio Liuzza, University of Magna Graecia, Italy

Reviewed by:

Martin Skov,

Copenhagen Business School,

Denmark

Cinzia Calluso,

Guido Carli Free International University for Social Studies, Italy

*Correspondence:

Nadège Bault

nadege_lab@nbault.net

Specialty section:

This article was submitted to

Theoretical and Philosophical

Psychology,

a section of the journal

Frontiers in Psychology

Received: 26 August 2019 Accepted: 19 December 2019

Published: 21 January 2020

Citation:

Bault N and Rusconi E (2020) The Art of Influencing Consumer Choices: A Reflection on Recent Advances

in Decision Neuroscience.

Front. Psychol. 10:3009

doi: 10.3389/fpsyg.2019.03009

\section{The Art of Influencing Consumer Choices: A Reflection on Recent Advances in Decision Neuroscience}

\author{
Nadège Bault ${ }^{1,2 *}$ and Elena Rusconi ${ }^{3}$ \\ ${ }^{1}$ School of Psychology, University of Plymouth, Plymouth, United Kingdom, ${ }^{2}$ Center for Mind/Brain Sciences (CIMeC), \\ University of Trento, Trento, Italy, ${ }^{3}$ Department of Psychology and Cognitive Science, University of Trento, Trento, Italy
}

In recent years, our knowledge concerning the neurobiology of choice has increased tremendously. Research in the field of decision-making has identified important brain mechanisms by which a representation of the subjective value of an option is built based on previous experience, retrieved and compared to that of other available options in order to make a choice. One body of research, in particular, has focused on simple value-based choices (e.g., choices between two types of fruits) to study situations very similar to our daily life decisions as consumers. The use of neuroimaging techniques has deepened and refined our knowledge of decision processes. Additionally, computational approaches have helped identifying and describing the mechanisms underlying newly found components of the decisional process. They provide mechanistic explanations for diverse biases that can drive decision makers away from their own preferences or from rational choices. It is now clear that both attentional and affective factors can exert robust effects on an individual's decisions. Because these factors can be manipulated externally, academic research and theories are of great interest to the marketing industry. This approach is becoming increasingly effective in manipulating consumer behavior and has the potential to become even more effective in the future. Another line of research has revealed differences in the decision-making neural circuitry that underlie suboptimal choice behavior, rendering some individuals particularly vulnerable to marketing strategies. As neuroscientists, we wonder whether relevant institutions should direct their efforts toward raising citizens' awareness, demanding more transparency on marketing applications and regulate the most pervasive communication techniques in marketing, in view of their current use and of recent research progress.

Keywords: value-based decisions, choice biases, marketing, regulation, decision neuroscience

\section{ATTENTIONAL BIASES IN CONSUMER CHOICES}

Tremendous progress has been realized in the last decade in our understanding of attentional effects on decision processes, through the description of their neurocomputational mechanisms. Thus, we will focus here on those mechanisms to illustrate how they can inform marketing strategies. Psychological and neural accounts of the role of memory and affective mechanisms in consumer decisions can be found in Plassmann and Karmarkar (2015).

\section{Cognitive and Neural Mechanisms of Simple Choice}

When facing a simple decision, for instance picking a fruit to eat in a basket containing several types of fruits, our brain computes a value signal. The value represents the expected benefit of 
consuming the good based on previous experience. Recent cognitive models of decision-making propose that a value is assigned to all the options available, then the values are compared in order to reach a decision (Rangel and Clithero, 2014). Expected delays, potential price, or uncertainty in its obtainment of the good will all be incorporated into the value signal. How exactly the value is computed, though, is still under scrutiny. Much evidence supports the theory that values are computed through reinforcement learning. A value is updated when our experience in consuming the good does not match our expectations, a mechanism that supports adaptive behavior. This learning mechanism is implemented in the brain by dopaminergic neurons of the ventral striatum. These neurons encode a prediction error signal which serves as an update signal for the value (Schultz, 1998; Tobler et al., 2005). They project to a frontal region called the ventromedial prefrontal cortex, which is thought to store the value signal (Ruff and Fehr, 2014). However, the way we value options often depends on our internal states (e.g., how hungry we are at that particular moment) and on states of the world (we might value more a juicy fruit in the summer than in the winter). Assuming that values of goods are stored globally fails to explain why choices can vary with the decision context.

Another theory proposes that we separately evaluate all attributes of the available options and integrate them at the time of choice (Rangel and Clithero, 2014). The value of an apple is not represented as such; rather, value associated with its color, taste, smell or shape are encoded separately. Considering the attributes of a good and retrieving the values associated with those attributes requires attention.

\section{The Influence of Attention on Decisions}

Krajbich and Rangel (2011) proposed that attention fluctuates among the different items being evaluated during a decision, and this affects the computation of their value. They applied a wellestablished model in perceptual decision-making (Ratcliff, 1978; Ratcliff et al., 2016) to simple value-based choices in order to characterize the link between attention - as measured by eye gaze and decision latency - to decision output through the hidden value computation process. Their attentional drift diffusion model (aDDM), applied to binary choices, states that the values of the attributes of the currently attended item are retrieved and integrated (Krajbich et al., 2010; but see Summerfield and Tsetsos, 2012; Calluso et al., 2015; for alternative drift diffusion models of value-based decision). At any point of time, the integrated value is then compared to the value of the unattended item. The agent freely explores the available options, switching their attention among the items. If the two items are appetitive (i.e., have been associated with positive experience in the past), the retrieval of their value will yield to a positive signal. While a specific item is being fixated, its value is computed and its relative value, compared to the other item, increases. When the difference between the values of the two items reaches a given threshold, the decision process terminates (Krajbich et al., 2010).

Evidence supporting this model is provided by experiments in perceptual decision-making (e.g., is the left segment shorter than the right one?) showing that in every choice, the firing rate of neurons increases proportionally to the easiness of the decision (integration process) and reaches the same point (threshold) right before an answer is given (Roitman and Shadlen, 2002; Gold and Shadlen, 2007). Moreover, during binary choices between snacks, the striatum and the ventromedial prefrontal cortex (i.e., two brain areas involved in valuation and choices) encode the value of the attended item, relatively to the value of the unattended item (Hare et al., 2011; Lim et al., 2011). Thus, attention modulates brain activity related to the retrieval and comparison of values.

The theory has several implications which have been verified experimentally. First, because the value of a desirable item increases when it is attended, the chosen item is the last one to be fixated before the threshold is reached and the decision is made. Second, the first fixated item gets an advantage in the value computation process and thus is more likely to be chosen. Third, the longer an item is being looked at the more likely it is that it will be chosen. Using repeated choices between snacks in combination with eye tracking, Krajbich et al. (2010) were able to confirm all those predictions. When choosing between two snacks equally liked by participants, they picked the last fixated item in about $75 \%$ of the trials. Moreover, the longest the first fixation, the higher the probability that the corresponding item would be chosen. Lastly, the longest an item was fixated and the higher was the probability it would be chosen, even after correcting for liking ratings. Importantly, similar choice biases induced by fixation trajectories were observed during purchasing decisions (Krajbich et al., 2012).

\section{Manipulating Attention to Bias Consumer Choices}

As decision processes are strongly influenced by visual exploration, this evidence may imply that externally orienting attention would result in systematic decision biases. Indeed, controlling the duration of visual presentation of the options can change judgments about the attractiveness of human faces (Shimojo et al., 2003) and about moral situations (Pärnamets et al., 2015). Decisions to acquire food or art items (Armel et al., 2008; Lim et al., 2011) $)^{1}$ can be biased as well. The likelihood that an item is chosen increases between 6 and $11 \%$ when it was seen for $900 \mathrm{~ms}$ rather than $300 \mathrm{~ms}$. Therefore, people have a bias to choose the things they have been viewing the longest rather than those they genuinely prefer. Gaze patterns reflect the preferences of individuals; they influence those preferences as well.

In addition, visually salient items would grab more attention (Itti and Koch, 2001), hence be fixated first and longer, and ultimately be chosen more often. Studies have shown that manipulating the visual saliency of stimuli by varying features such as intensity, color, and orientation results in participants making a choice that contradicts their initial preferences (Navalpakkam et al., 2010; Towal et al., 2013). These effects extend to purchasing environments, where

\footnotetext{
${ }^{1} \mathrm{~A}$ demonstration of the effect is available in a TEDx talk delivered by Antonio
} Rangel (http://www.tedxcaltech.com/content/antonio-rangel). 
they can become even stronger when the cognitive load is high. The color, and brightness of the packaging can lead individuals to choose their least preferred product under time pressure (Milosavljevic et al., 2012). Similarly, the probability that individuals will pick the brand they value the most in a supermarket shelf decreases as the number of available products increases. They tend to grab the product right in front of them. Because of reading habits, in occidental countries, options placed in the top left corner are chosen more often than those in lower right corner (Reutskaja et al., 2011).

\section{Applications in Marketing}

Clearly, advertisers did not wait for psychologists and neuroscientists to describe the cognitive mechanisms of the attention grabbing effects on decisions to exploit them (Pieters and Wedel, 2004). Nonetheless as academic research makes progress in identifying decision biases, precisely describing the variables that can cause these biases in more and more refined theoretical models, advertising and other marketing techniques will become more effective. In fact, many efforts are directed into bridging neuroscience research with marketing both at the academic and at the industry levels (Plassmann et al., 2007; Karmarkar and Plassmann, 2019). Marketing companies are now equipped with a more mechanistic understanding of decisions processes and various neuroscientific tools to measure affective responses (skin conductance responses, pupil dilatation), attentional effects (eye movements, mouse movements), and brain responses elicited by products.

One particularly problematic ethical concern that derives from those new approaches is the ability to target specific individuals or groups of individuals (Stanton et al., 2017) via the systematic monitoring of consumers' behavior, both online and in shops and the use of big data techniques to profile them (Aguirre et al., 2015; Boerman et al., 2017). The goal is to identify the putative needs of categories of consumers in order to focus the marketing strategy on selected goods susceptible to fill those needs. There are several risks associated with this practice, one being an increased consumerism and increased prices paid by consumers (Stanton et al., 2017). Another risk is to exploit the vulnerabilities of individuals. For instance, individuals, with compulsive buying disorders (Black, 2007) are particularly sensitive to encouragements to buy on the web (Rose and Dhandayudham, 2014). Marketing techniques can potentially have detrimental consequences on several groups of the population.

\section{INTER-INDIVIDUAL DIFFERENCES IN DECISION-MAKING AND VULNERABILITY TO MARKETING}

Large inter-individual differences exist, both in decision mechanisms and their susceptibility to external influence. During development and aging, individuals tend to make less advantageous choices and are more susceptible to the influence of marketing techniques. Addiction and eating disorders can deeply tamper with the ability of making healthy choices. Recent advances in cognitive psychology and neuroscience can help understand why many individuals struggle in making sound choices.

\section{Children and Adolescents}

Compared to adults, adolescents engage more in risky behavior (Steinberg, 2008) and display heightened peer-influence in their daily choices (van Hoorn et al., 2016). The uneven neurodevelopmental trajectories of the brain systems implicated in processing rewards on one side, and those involved in cognitive control on the other can explain these behavioral characteristics (Casey et al., 2008). The hyper-reactivity of the reward system, especially in the striatum is associated with emotional hypersensitivity to rewarding stimuli, faces and socioemotional stimuli (Galvan et al., 2006; Casey et al., 2008; Hare et al., 2008). By contrast, the maturation of the prefrontal cortex, involved in cognitive control, still continues until about the age of 20 (Gogtay et al., 2004; Shaw et al., 2008).

Younger consumers constitute a substantial part of the market and marketers and advertisers have developed a large spectrum of strategies to reach them (Valkenburg and Cantor, 2001). The interest for marketing in children and adolescents lays in the realization that, in the last decades, they have acquired higher financial independence and more influence in household purchasing decisions. Children develop brand loyalty at an early age (Haryanto et al., 2016), which persists until adulthood. Detrimental effects of advertising on the development of children's consumption habits is well documented (Wilcox et al., 2004). Television commercials targeted at children, in particular, are highly effective (Atkin, 1978; Gorn and Goldberg, 1982). They have been reported to induce unhealthy eating habits, to cultivate a materialistic value system and to be a source of conflicts between children and their parents (Goldberg and Gorn, 1978; Gorn and Goldberg, 1982; Story and French, 2004).

\section{Older Adults}

Aging individuals constitute a particularly vulnerable population as well. Older individuals make more disadvantageous decisions, especially in uncertain or changing environments. One exception is the ability to make more farsighted decisions with age (Samanez-Larkin and Knutson, 2015) which can potentially lead to better consumer choices (Zauberman and Urminsky, 2016). However, older adults borrow at higher interest rates and pay more fees to financial institutions than their younger counterparts (Agarwal et al., 2007); they are less consistent in health-related decisions (Löckenhoff and Carstensen, 2007). Most importantly they are more sensitive to deceptive advertising than their younger counterparts (Denburg et al., 2007). Older adults' heightened susceptibility to misleading advertising techniques can be explained by a reduced ability to discriminate between potentially misleading and more truthful advertising claims (Gaeth and Heath, 1987). They tend as well to give higher credit to claims that are repeated. Strikingly, even if they are informed that a claim is false, they will remember it as true a few days later (Skurnik et al., 2005). Decision deficits that arise 
with age in variable or uncertain environments might be due to cognitive limitations (Henninger et al., 2010; van de Vijver et al., 2015). Deficits in valuation processes have been also reported at the neural level, as structural changes in frontostriatal pathways are linked to disadvantageous decisions (Samanez-Larkin and Knutson, 2015; van de Vijver et al., 2016).

\section{Inter-Individual Differences in Self-Control}

Individuals differ widely in their ability to implement self-control in their daily choices and maintain goal-directed behavior. Economists explain these disparities by considering interindividual differences in discounting the long term consequences of choice options in the computation of their value (Laibson, 1997; O’Donoghue and Rabin, 1999). Psychologists approach this question by considering the relative difficulty and reliability of representing immediate pleasurable attributes and more abstract and temporally distant attributes of options (Liberman and Trope, 2008). When applied to self-control in dietary choices, eating a chocolate cake rather than an apple can be explained by the overweighing of taste compared to health information. A computational approach showed that up to $39 \%$ of the variability in dietary self-control failures can be explained by the speed with which the decision-making circuitry processes basic attributes like taste, versus more abstract attributes such as health (Sullivan et al., 2015). The biological plausibility of this model was supported by the finding that variability in diet success is linked to the relative representation of taste and health attributes in the ventromedial prefrontal cortex (Hare et al., 2009). According to the authors, "these findings provide a rationale for regulating marketing practices that increase the relative ease with which abstract attributes such as health are processed. For example, prominently displaying health information such as calorie counts may allow more rapid integration of health attributes" (Sullivan et al., 2015, p. 133).

In sum, the brain structures involved in motivation and decision-making are the latest to be fully functional during development and decline relatively early with age (Somerville and Casey, 2010; Samanez-Larkin and Knutson, 2015). As a result, maintaining goal-directed behavior in the long term and resisting temptations can be difficult at young age. Later in life, flexibly adapting to changing decision environments can become challenging (Eppinger et al., 2011). During adult life, unhealthy habits can readily form and several biological or societal factors can dysregulate the balance of the decision-making and motivation brain circuitry. Thus, large portion of the population is susceptible to be negatively impacted by marketing techniques and make disadvantageous decision or forming unhealthy habits, at least during certain period of their lives.

\section{ADVERTISING REGULATION}

The realization of the increasing potential of neuroscientific knowledge applied to marketing raises a few questions. Does this always represent an advantage to us as a society and as individuals? If not, should (more) regulations be put in place to avert potential damage?

\section{Why Regulate Advertising?}

In a world full of temptations carried by pervasive marketing messages, making decisions consistent with one's own goals and preferences requires constant self-control. Extensive research has revealed that self-control often fails when individuals experience emotional distress (Baumeister et al., 1994). Excessive exposure to social norms brought by advertisement can induce emotional distress in vulnerable populations such as addicts or individuals with eating disorders. For instance, exposure to thin models in advertisement induces body-focused anxiety among women (Halliwell and Dittmar, 2004).

Research on the psychological consequences of poverty indicates a link between low income, stress and short-sighted, disadvantageous economical decisions (Haushofer and Fehr, 2014). In addition, financial scarcity causes a reduction in cognitive control (Mani et al., 2013), as well as changes in attention allocation; salient information relative to short-term decisions receive more attention than information concerning the future, which can cause bad economic decisions such as overborrowing (Shah et al., 2012). Consequently, we might reasonably expect that poorer individuals can be negatively affected by advertising. While positive nudging can elicit people to save more (Karlan et al., 2016), tempting advertising or branding effects can easily lead to over-spending. Whether overexposure to marketing messages is linked to decreased well-being and increased level of stress or emotional distress in the general population is unknown, although some authors suggest it is likely to be the case (Baumeister, 2002; Sullivan et al., 2015). Research investigating this question is crucially needed in order to have a sound scientific dialogue about the "dark side of consumer neuroscience” (Kenning and Plassmann, 2008).

Internet advertising, in particular, potentially constitutes a serious concern. Internet ads are present in the visual field of consumers even when not directly attended. Several studies have shown that the value associated with specific stimuli are retrieved and updated by our reward system even when passively viewed (Lebreton et al., 2009; Tusche et al., 2010; Smith et al., 2014). Passive viewing of products of a specific brand have direct effect on purchase decisions (Ferraro et al., 2009). Additionally, with the generalization of online shopping, ads are present in the visual field of the buyer right at the moment of purchasing decisions. The use of internet data enables the tailoring of adverts by proposing to specific consumers those products they would be more likely to purchase. Online targeted advertising, through the monitoring of people's online behavior triggers an increase in the rate of clicking on the ads as well as higher likelihood of purchase (Boerman et al., 2017), although the size of reported effects varies deeply between academic studies and claims made by advertising agencies.

\section{How to Regulate Advertising?}

An efficient and self-regulated market rests on the ability for firms to inform consumers about their novel products and stimulate them to buy those products. Yet, this should not be done at 
the expense of individuals' mental, physical or financial health. Neither should marketing strategies drive consumers away from their explicit goals and intentions, such as staying on a diet or reducing their use of products with high environmental impact. While people with strong initial preferences are less likely to see their choice behavior dramatically influenced by marketing techniques, the latter are more efficient on individuals whose preferences have not yet formed such as children, vulnerable groups or individuals with conflicting motivations.

We believe that expanding our knowledge about decision mechanisms and how to modulate them is not inherently problematic as many beneficial applications, for individuals and for the society, can arise. The rehabilitation of addictive disorders is one important application. Nudging, which can be considered as the 'good' counterpart to marketing, relies on very similar theories and techniques to influence individuals' behavior to make it more in line with their intentions. One previously mentioned example is the use of reminders to save money. Another example is the so called 'green-nudging' (Schubert, 2017; Bonini et al., 2018) which prompts people to make ecologically responsible decisions. The key difference between marketing and nudging lies in the very idea of adequacy between the declared intentions of the customer (e.g., follow a specific diet, make ecologically responsible purchases) and the type of manipulation being exerted on their behavior. In addition, nudging is usually initiated by public institutions with the end goal of benefiting the society. For instance, nudging might encourage more ecologically responsible consumption by displaying the environment impact of products, but it will never orient consumers toward a specific brand. Public acceptability of nudging is generally positive (Reynolds et al., 2019) while advertising made by companies motivated by profit is controversial. Therefore, the very idea of transparency from the part of the advertising company and consent from the customer seems crucial. Policy makers could consider empowering citizens by letting them decide whether they accept to be exposed to different types of advertising.

Strikingly, the legal system of several countries has adjudicated that promoting products which threaten public health should be prohibited. Advertisement of products containing tobacco or alcohol is strictly forbidden in many countries. In addition, the branding effect of cigarettes is reduced by including pictures of dramatic health consequences of smoking on packaging. Similarly, attempts to reduce the prevalence of obesity, diabetes and hypertension have been made by trying to limit the effectiveness of advertisements on high caloric food and beverages with associated warning messages. For instance, in 2007 in France, a law was adopted listing categories of nutritive products (e.g., sweets and sodas) whose advertisement had to contain a message suggesting to eat more fruits and vegetable, increase physical activity and reduce salt and sugar intake. Thus, the approach adopted so far to protect the population from potential detrimental effects of advertising focuses on specific products and age groups (mainly children). Nonetheless, as discussed earlier the potential damage of advertising extent to many groups of individuals.

A possibly efficient approach could be to limit the intrusive aspects of the advertising means, in order to allow vulnerable individuals, especially those with compulsive or addictive tendencies, to maintain self-protective strategies. Measures should be taken to prevent advertisement to be forced into the peripheral visual field of individuals attending a nearby focal point of interest. In order to avoid passive viewing, it could entail the prohibition of advertising messages in confined public spaces (e.g., bus stops) and in locations surrounding informative or salient focal point (e.g., information panels). One particularly striking example is the advertisement low-cost airplane companies place on the seat in front of their clients to incite them to buy snacks. Such practice is extremely intrusive as people cannot easily look away. Similarly, if advertisement in magazines would be on their own separate page, rather than next to an informative article, consumers would still have the opportunity of being informed of new products while controlling the degree of exposure to advertisement they are willing to accept. Internet ads could be forced in their own browser tab instead of being placed next to the focus of attention of users. A mandatory op-out option for specific categories of products would also be desirable to help individuals struggling with addictive behavior or eating disorders. The important aspect in this proposition is to allow consumers to regain control in their exposure to advertisement by having them consent to viewing ads through a motor action (such as clicking on the ads tab), rather than forcing passive viewing.

\section{CONCLUSION}

Due to our increasing knowledge of decision mechanisms and the increasing efficiency and outreach of communication means, marketing techniques are becoming both intrusive and powerful. The brain circuitry for decision and motivation changes during the lifespan or due to a diversity of contingent and individual factors. Because of our growing understanding of vulnerabilities to external influences, it is perhaps time to address the issue of intrusiveness of advertisement at a societal level and consider regulatory intervention.

\section{AUTHOR CONTRIBUTIONS}

$\mathrm{NB}$ and ER prepared and validated the manuscript.

\section{FUNDING}

This work was funded by the European Research Council (ERC Consolidator Grant 617629). 


\section{REFERENCES}

Agarwal, S., Driscoll, J. C., Gabaix, X., and Laibson, D. (2007). The Age of Reason: Financial Decisions Over the Lifecycle. Cambridge, MA: National Bureau of Economic Research, doi: 10.3386/w13191

Aguirre, E., Mahr, D., Grewal, D., de Ruyter, K., and Wetzels, M. (2015). Unraveling the personalization paradox: the effect of information collection and trustbuilding strategies on online advertisement effectiveness. J. Retail. 91, 34-49. doi: 10.1016/j.jretai.2014.09.005

Armel, K. C., Beaumel, A., and Rangel, A. (2008). Biasing simple choices by manipulating relative visual attention. Judg. Decision Making 3, 396-403.

Atkin, C. K. (1978). Observation of parent-child interaction in supermarket decision-making. J. Mark. 42, 41-45. doi: 10.1177/00222429780420 0406

Baumeister, R. F. (2002). Yielding to temptation: self-control failure, impulsive purchasing, and consumer behavior. J. Consum. Res. 28, 670-676. doi: 10.1086/ 338209

Baumeister, R. F., Heatherton, T. F., and Tice, D. M. (1994). Losing Control: How and Why People Fail at Self-Regulation, 1 Edn. San Diego: Academic Press.

Black, D. W. (2007). Compulsive buying disorder: a review of the evidence. CNS Spectr. 12, 124-132. doi: 10.1017/S1092852900020630

Boerman, S. C., Kruikemeier, S., and Borgesius, F. J. Z. (2017). Online behavioral advertising: a literature review and research Agenda. J. Advert. 46, 363-376. doi: 10.1080/00913367.2017.1339368

Bonini, N., Hadjichristidis, C., and Graffeo, M. (2018). Green nudging. Acta Psychol. Sin. 50, 814-826. doi: 10.3724/SP.J.1041.2018.00814

Calluso, C., Committeri, G., Pezzulo, G., Lepora, N., and Tosoni, A. (2015). Analysis of hand kinematics reveals inter-individual differences in intertemporal decision dynamics. Exp. Brain Res. 233, 3597-3611. doi: 10.1007/ s00221-015-4427-1

Casey, B. J., Jones, R. M., and Hare, T. A. (2008). The adolescent brain. Ann. N. Y. Acad. Sci. 1124, 111-126. doi: 10.1196/annals. 1440.010

Denburg, N. L., Cole, C. A., Hernandez, M., Yamada, T. H., Tranel, D., Bechara, A., et al. (2007). The orbitofrontal cortex, real-world decision making, and normal aging. Ann. N. Y. Acad. Sci. 1121, 480-498. doi: 10.1196/annals.1401.031

Eppinger, B., Hämmerer, D., and Li, S.-C. (2011). Neuromodulation of rewardbased learning and decision making in human aging. Ann. N. Y. Acad. Sci. 1235, 1-17. doi: 10.1111/j.1749-6632.2011.06230.x

Ferraro, R., Bettman, J. R., and Chartrand, T. L. (2009). The power of strangers: the effect of incidental consumer brand encounters on brand choice. J. Consum. Res. 35, 729-741. doi: 10.1086/592944

Gaeth, G. J., and Heath, T. B. (1987). The cognitive processing of misleading advertising in young and old adults: assessment and training. J. Consum. Res. 14, 43-54. doi: 10.1086/209091

Galvan, A., Hare, T. A., Parra, C. E., Penn, J., Voss, H., Glover, G., et al. (2006). Earlier development of the accumbens relative to orbitofrontal cortex might underlie risk-taking behavior in adolescents. J. Neurosci. 26, 6885-6892. doi: 10.1523/JNEUROSCI.1062-06.2006

Gogtay, N., Giedd, J. N., Lusk, L., Hayashi, K. M., Greenstein, D., Vaituzis, A. C., et al. (2004). Dynamic mapping of human cortical development during childhood through early adulthood. PNAS 101, 8174-8179. doi: 10.1073/pnas. 0402680101

Gold, J. I., and Shadlen, M. N. (2007). The neural basis of decision making. Annu. Rev. Neurosci. 30, 535-574. doi: 10.1146/annurev.neuro.29.051605.113038

Goldberg, M. E., and Gorn, G. J. (1978). Some unintended consequences of TV advertising to children. J. Consum. Res. 5, 22-29. doi: 10.1086/208710

Gorn, G. J., and Goldberg, M. E. (1982). Behavioral evidence of the effects of televised food messages on children. J. Consum. Res. 9, 200-205. doi: 10.1086/ 208913

Halliwell, E., and Dittmar, H. (2004). Does size matter? the impact of model's body size on women's body-focused anxiety and advertising effectiveness. J. Soc. Clin. Psychol. 23, 104-122. doi: 10.1521/jscp.23.1.104.26989

Hare, T. A., Camerer, C. F., and Rangel, A. (2009). Self-control in decision-making involves modulation of the vmPFC valuation system. Science 324, 646-648. doi: $10.1126 /$ science. 1168450

Hare, T. A., O’Doherty, J., Camerer, C. F., Schultz, W., and Rangel, A. (2008). Dissociating the role of the orbitofrontal cortex and the striatum in the computation of goal values and prediction errors. J. Neurosci. 28, 5623-5630. doi: 10.1523/ineurosci.1309-08.2008

Hare, T. A., Schultz, W., Camerer, C. F., O’Doherty, J. P., and Rangel, A. (2011). Transformation of stimulus value signals into motor commands during simple choice. Proc. Natl. Acad. Sci. 108, 18120-18125. doi: 10.1073/pnas.1109322108

Haryanto, J. O., Moutinho, L., and Coelho, A. (2016). Is brand loyalty really present in the children's market? A comparative study from Indonesia, Portugal, and Brazil. J. Bus. Res. 69, 4020-4032. doi: 10.1016/j.jbusres.2016.06.013

Haushofer, J., and Fehr, E. (2014). On the psychology of poverty. Science 344, 862-867. doi: 10.1126/science. 1232491

Henninger, D. E., Madden, D. J., and Huettel, S. A. (2010). Processing speed and memory mediate age-related differences in decision making., processing speed and memory mediate age-related differences in decision making. Psychol. Aging 25, 262-270. doi: 10.1037/a 0019096

Itti, L., and Koch, C. (2001). Computational modelling of visual attention. Nat. Rev. Neurosci. 2, 194-203. doi: $10.1038 / 35058500$

Karlan, D., McConnell, M., Mullainathan, S., and Zinman, J. (2016). Getting to the top of mind: how reminders increase saving. Manag. Sci. 62, 3393-3411. doi: $10.1287 / \mathrm{mnsc} .2015 .2296$

Karmarkar, U. R., and Plassmann, H. (2019). Consumer neuroscience: past. present, and future. Org. Res. Methods 22, 174-195. doi: 10.1177/ 1094428117730598

Kenning, P. H., and Plassmann, H. (2008). How neuroscience can inform consumer research. IEEE Trans. Neural Syst. Rehabil. Eng. 16, 532-538. doi: 10.1109/TNSRE.2008.2009788

Krajbich, I., Armel, C., and Rangel, A. (2010). Visual fixations and the computation and comparison of value in simple choice. Nat. Neurosci. 13, 1292-1298. doi: $10.1038 / \mathrm{nn} .2635$

Krajbich, I., Lu, D., Camerer, C., and Rangel, A. (2012). The attentional driftdiffusion model extends to simple purchasing decisions. Front. Psychol. 3:193. doi: $10.3389 /$ fpsyg. 2012.00193

Krajbich, I., and Rangel, A. (2011). Multialternative drift-diffusion model predicts the relationship between visual fixations and choice in value-based decisions. Proc. Natl. Acad. Sci. U.S.A. 108, 13852-13857. doi: 10.1073/pnas.1101328108

Laibson, D. (1997). Golden eggs and hyperbolic discounting. Q. J. Econ. 112, 443-478. doi: 10.1162/003355397555253

Lebreton, M., Jorge, S., Michel, V., Thirion, B., and Pessiglione, M. (2009). An automatic valuation system in the human brain: evidence from functional neuroimaging. Neuron 64, 431-439. doi: 10.1016/j.neuron.2009.09.040

Liberman, N., and Trope, Y. (2008). The psychology of transcending the here and now. Science 322, 1201-1205. doi: 10.1126/science.1161958

Lim, S.-L., O'Doherty, J. P., and Rangel, A. (2011). The decision value computations in the vmPFC and striatum use a relative value code that is guided by visual attention. J. Neurosci. 31, 13214-13223. doi: 10.1523/JNEUROSCI. $1246-11.2011$

Löckenhoff, C. E., and Carstensen, L. L. (2007). Aging, emotion, and health-related decision strategies: motivational manipulations can reduce age differences. Psychol. Aging 22, 134-146. doi: 10.1037/0882-7974.22.1.134

Mani, A., Mullainathan, S., Shafir, E., and Zhao, J. (2013). Poverty impedes cognitive function. Science 341, 976-980. doi: 10.1126/science.1238041

Milosavljevic, M., Navalpakkam, V., Koch, C., and Rangel, A. (2012). Relative visual saliency differences induce sizable bias in consumer choice. J. Consum. Psychol. 22, 67-74. doi: 10.1016/j.jcps.2011.10.002

Navalpakkam, V., Koch, C., Rangel, A., and Perona, P. (2010). Optimal reward harvesting in complex perceptual environments. Proc. Natl. Acad. Sci. U.S.A. 107, 5232-5237. doi: 10.1073/pnas.0911972107

O'Donoghue, T., and Rabin, M. (1999). Doing it now or later. Am. Econ. Rev. 89, 103-124. doi: 10.1257/aer.89.1.103

Pärnamets, P., Johansson, P., Hall, L., Balkenius, C., Spivey, M. J., and Richardson, D. C. (2015). Biasing moral decisions by exploiting the dynamics of eye gaze. PNAS 112, 4170-4175. doi: 10.1073/pnas.1415250112

Pieters, R., and Wedel, M. (2004). Attention capture and transfer in advertising: brand, pictorial, and text-size effects. J. Mark. 68, 36-50. doi: 10.1509/jmkg.68. 2.36.27794

Plassmann, H., Ambler, T., Braeutigam, S., and Kenning, P. (2007). What can advertisers learn from neuroscience? Int. J. Advert. 26, 151-175. doi: 10.1080/ 10803548.2007 .11073005 
Plassmann, H., and Karmarkar, U. R. (2015). “Consumer neuroscience: revealing meaningful relationships between brain and consumer behavior," in The Cambridge Handbook of Consumer Psychology, eds M. I. Norton, D. D. Rucker, and C. Lamberton, (Cambridge, MA: Cambridge University Press), 152-179. doi: $10.1017 /$ CBO9781107706552.006

Rangel, A., and Clithero, J. A. (2014). "The computation of stimulus values in simple choice," in Neuroeconomics, ed. P. W. Glimcher, (Amsterdam: Elsevier), 125-148. doi: 10.1016/B978-0-12-416008-8.00008-5

Ratcliff, R. (1978). A theory of memory retrieval. Psychol. Rev. 85, 59-108. doi: 10.1037/0033-295X.85.2.59

Ratcliff, R., Smith, P. L., Brown, S. D., and McKoon, G. (2016). Diffusion decision model: current issues and history. Trends Cogn. Sci. 20, 260-281. doi: 10.1016/ j.tics.2016.01.007

Reutskaja, E., Nagel, R., Camerer, C. F., and Rangel, A. (2011). Search dynamics in consumer choice under time pressure: an eye-tracking study. Am. Econ. Rev. 101, 900-926. doi: 10.1257/aer.101.2.900

Reynolds, J. P., Archer, S., Pilling, M., Kenny, M., Hollands, G. J., and Marteau, T. M. (2019). Public acceptability of nudging and taxing to reduce consumption of alcohol, tobacco, and food: a population-based survey experiment. Soc. Sci. Med. 236, 112395. doi: 10.1016/j.socscimed.2019.112395

Roitman, J. D., and Shadlen, M. N. (2002). Response of neurons in the lateral intraparietal area during a combined visual discrimination reaction time task. J. Neurosci. 22, 9475-9489. doi: 10.1523/JNEUROSCI.22-21-09475. 2002

Rose, S., and Dhandayudham, A. (2014). Towards an understanding of Internetbased problem shopping behaviour: the concept of online shopping addiction and its proposed predictors. J. Behav. Addict. 3, 83-89. doi: 10.1556/JBA.3. 2014.003

Ruff, C. C., and Fehr, E. (2014). The neurobiology of rewards and values in social decision making. Nat. Rev. Neurosci. 15, 549-562. doi: 10.1038/nrn3776

Samanez-Larkin, G. R., and Knutson, B. (2015). Decision making in the ageing brain: changes in affective and motivational circuits. Nat. Rev. Neurosci. 16, 278-289. doi: 10.1038/nrn3917

Schubert, C. (2017). Green nudges: do they work? Are they ethical? Ecol. Econ. 132, 329-342. doi: 10.1016/j.ecolecon.2016.11.009

Schultz, W. (1998). Predictive reward signal of dopamine neurons. J. Neurophysiol. 80, 1-27. doi: 10.1152/jn.1998.80.1.1

Shah, A. K., Mullainathan, S., and Shafir, E. (2012). Some consequences of having too little. Science 338, 682-685. doi: 10.1126/science.1222426

Shaw, P., Kabani, N. J., Lerch, J. P., Eckstrand, K., Lenroot, R., Gogtay, N., et al. (2008). Neurodevelopmental trajectories of the human cerebral cortex. J. Neurosci. 28, 3586-3594. doi: 10.1523/JNEUROSCI.5309-07.2008

Shimojo, S., Simion, C., Shimojo, E., and Scheier, C. (2003). Gaze bias both reflects and influences preference. Nat. Neurosci. 6, 1317-1322. doi: 10.1038/nn1150

Skurnik, I., Yoon, C., Park, D. C., and Schwarz, N. (2005). How warnings about false claims become recommendations. J. Consum. Res. 31, 713-724. doi: 10. $1086 / 426605$

Smith, A., Bernheim, B. D., Camerer, C., and Rangel, A. (2014). Neural activity reveals preferences without choices. Am. Econ. J. Microecon. 6, 1-36. doi: 10. 1257/mic.6.2.1

Somerville, L. H., and Casey, B. (2010). Developmental neurobiology of cognitive control and motivational systems. Curr. Opin. Neurobiol. 20, 236-241. doi: 10.1016/j.conb.2010.01.006
Stanton, S. J., Sinnott-Armstrong, W., and Huettel, S. A. (2017). Neuromarketing: ethical implications of its use and potential misuse. J. Bus. Ethics 144, 799-811. doi: 10.1007/s10551-016-3059-0

Steinberg, L. (2008). A social neuroscience perspective on adolescent risk-taking. Curr. Direct. Risk Decis. Making 28, 78-106. doi: 10.1016/j.dr.2007.08.002

Story, M., and French, S. (2004). Food advertising and marketing directed at children and adolescents in the US. Int. J. Behav. Nutr. Phys. Act. 1:3. doi: 10.1186/1479-5868-1-3

Sullivan, N., Hutcherson, C., Harris, A., and Rangel, A. (2015). Dietary self-control is related to the speed with which attributes of healthfulness and tastiness are processed. Psychol. Sci. 26, 122-134. doi: 10.1177/0956797614559543

Summerfield, C., and Tsetsos, K. (2012). Building bridges between perceptual and economic decision-making: neural and computational mechanisms. Front. Neurosci. 6:70. doi: 10.3389/fnins.2012.00070

Tobler, P. N., Fiorillo, C. D., and Schultz, W. (2005). Adaptive coding of reward value by dopamine neurons. Science 307, 1642-1645. doi: 10.1126/science. 1105370

Towal, R. B., Mormann, M., and Koch, C. (2013). Simultaneous modeling of visual saliency and value computation improves predictions of economic choice. Proc. Natl. Acad. Sci. 110, E3858-E3867. doi: 10.1073/pnas.1304429110

Tusche, A., Bode, S., and Haynes, J.-D. (2010). Neural responses to unattended products predict later consumer choices. J. Neurosci. 30, 8024-8031. doi: 10. 1523/JNEUROSCI.0064-10.2010

Valkenburg, P. M., and Cantor, J. (2001). The development of a child into a consumer. J. Appl. Dev. Psychol. 22, 61-72. doi: 10.1016/S0193-3973(00)00 066-6

van de Vijver, I., Ridderinkhof, K. R., and de Wit, S. (2015). Age-related changes in deterministic learning from positive versus negative performance feedback. Aging Neuropsychol. Cogn. 22, 595-619. doi: 10.1080/13825585.2015.1020917

van de Vijver, I., Ridderinkhof, K. R., Harsay, H., Reneman, L., Cavanagh, J. F., Buitenweg, J. I. V., et al. (2016). Frontostriatal anatomical connections predict age- and difficulty-related differences in reinforcement learning. Neurobiol. Aging 46, 1-12. doi: 10.1016/j.neurobiolaging.2016.06.002

van Hoorn, J., Fuligni, A. J., Crone, E. A., and Galván, A. (2016). Peer influence effects on risk-taking and prosocial decision-making in adolescence: insights from neuroimaging studies. Curr. Opin. Behav. Sci. 10, 59-64. doi: 10.1016/j. cobeha.2016.05.007

Wilcox, B. L., Kundel, D., Cantor, J., Dowrick, P., Linn, S., and Palmer, E. (2004). Report of the APA Task Force on Advertising and Children. Washington, D.C: American Psychological Association, doi: 10.1037/e539692009-001

Zauberman, G., and Urminsky, O. (2016). Consumer intertemporal preferences. Curr. Opin. Psychol. 10, 136-141. doi: 10.1016/j.copsyc.2016.01.005

Conflict of Interest: The authors declare that the research was conducted in the absence of any commercial or financial relationships that could be construed as a potential conflict of interest.

Copyright (C) 2020 Bault and Rusconi. This is an open-access article distributed under the terms of the Creative Commons Attribution License (CC BY). The use, distribution or reproduction in other forums is permitted, provided the original author(s) and the copyright owner(s) are credited and that the original publication in this journal is cited, in accordance with accepted academic practice. No use, distribution or reproduction is permitted which does not comply with these terms. 